\title{
Kate Millet, Sexual Politics e os diálogos entre diferentes paradigmas e ondas feministas
}

Kate Millet, Sexual Politics and dialogues established between different feminist paradigms and waves

\section{Liane Schneider}

Universidade Federal da Paraíba - UFPB - João Pessoa - Paraíba - Brasil

Resumo: Este artigo revisa os impactos do livro Sexual Politics (1970), de Kate Millet para a área dos estudos feministas e de gênero nas décadas que seguiram sua publicação, ou seja, os anos setenta, principalmente em pesquisas desenvolvidas no campo literário. A proposta é apontar os indícios que Millet apresenta naquele momento quanto à pluralidade que futuramente viria a marcar de forma determinante os conceitos de 'mulher'/ 'mulheres' dentro das teorias feministas. Millet busca demonstrar como se organizou a revolução sexual no contexto anglo-americano, branco e, em sua maioria, heterossexual, mas por um panorama bastante pormenorizado. Dessa forma, através da rediscussão de seu texto, busco colocar o mesmo em diálogo com a produção de outras teóricas que revisaram as estórias do feminismo pela perspectiva histórica, como Clare Hemmings e a produção teórico-crítica das mulheres de cor estadunidenses, principalmente de Anzaldúa. A partir destes diálogos concluo que, ainda que o foco central de Millet não tenha sido a explosão da categoria 'mulher', através da visão de diferentes agendas revolucionárias, as pluralidades que marcariam a construção do sujeito do feminismo já permeavam seu texto, ideia que só mais tarde se tornaria central ao pensamento feminista.

Palavras-chave: Kate Millet. Sexual Politics. Histórias das teorias feministas.

Abstract: This article revises the impacts of Sexual Politics (1970), by Kate Millet for gender, feminist and literary studies after its publication. The idea is to point out indications presented by Millet of future pluralities that would become determinant in relation to concepts of woman/women for feminist theories. Her discourse was centered in the Anglo-American context, and in such context, her focus was mainly on white and heterosexual subjectivities at that moment. However, as a matter of fact, she ended up covering a much broader view of the cultural field. Thus, departing from the discussion of her publication from the sixties/seventies, I try to put it into dialogue with the production of other theoreticians that also revised the history of feminism through historical lenses, such as Clare Hemmings, and the production of women of color in the United States of America, mainly as developed by Anzaldúa. From observing such juxtaposition of texts and the possible but difficult dialogue resulting from it, I conclude that, although Millet's central focus has not been the explosion with the category "woman" into different revolutionary agendas, pluralities that would mark the construction of the subject of feminism were already permeating her study, what would later become central to contemporary feminist studies.

Keywords: Kate Millet. Sexual Politics. History of feminist theories. 


\section{Introdução}

Não existe outra saída para tal dilema senão a revolta - mas o rebelde ver-se-á esmagado, estigmatizado e "tratado". Enquanto não conseguirmos ressuscitar o espírito radical que nos libertará, permaneceremos aprisionados na vastidão das sombrias e esconsas clausuras da reação sexual. (Kate Millet, 1970)

Minha proposta ao longo desse artigo é construir um olhar revisionista do livro Sexual Politics (1970), de Kate Millet, verificando as trocas que esse estabeleceu e continua a estabelecer com outras teorias e críticas feministas no campo dos estudos literários e culturais. Inicialmente, enfoco a dita segunda onda feminista, com raízes na Europa e, principalmente, nos Estados Unidos ao longo dos anos setenta, que só chegaria a impactar o contexto brasileiro nas décadas de oitenta e noventa do século passado. Os estudos feministas, a partir de então, passaram a brotar e florescer nas várias esferas acadêmicas do Brasil, estabelecendo diálogos com os feminismos de outras partes do mundo, que continuaram a se espalhar e diferenciar pelos vários continentes. Aqui, tornaram-se, nas décadas seguintes, foco de muitas estudantes ávidas por discutir conceitos sobre o que seria a mulher (e, mais tarde, as mulheres), a cultura, direitos $\mathrm{e}$ desigualdades, entre as quais me incluo. Para além das questões de gênero, há que se ter em mente que as concepções de identidade e de sujeito ainda eram, naquele momento, muito atreladas a grupos (então ditos) hegemônicos (no que dizia respeito à raça e/ou classe), com todos os privilégios agregados, privilégios esses pouco reconhecidos e problematizados à época, quer pelos discursos da sociedade brasileira mais ampla, quer pelo debate feminista.

Foi nesse contexto que tive contato com a publicação de Kate Millet, tendo ficado de imediato impressionada pela informação obtida de que Sexual Politics (1970) seria provavelmente uma das teses de doutorado mais lidas no mundo, um absoluto sucesso editorial. Enquanto buscava abrir minhas próprias veredas de pesquisa entre tantas novidades teóricas com as quais estabelecia contato, carregando para cima e para baixo sacolas cheias de livros emprestados por minha então orientadora a fim de serem copiados, lidos e rabiscados, pareceu-me reconfortante saber que alguém escrevera uma tese que se tornara um sucesso editorial, lida e relida mundo afora. $\mathrm{E}$, ainda melhor, saber que esse alguém era uma mulher, nascida na década de trinta, que não tinha origem nas famílias mais tradicionais estadunidenses e que circulava com certa liberdade por entre estudos literários e diferentes práticas artísticas, tendo conquistado seu crescimento profissional e social através da própria educação.

Millet lia a sociedade e o que viria a ser denominado de sistema de gênero (pela própria, mas também por Lauretis em "Tecnologias de gênero") com olhos muito interessados nas desigualdades (econômicas, sexuais, profissionais) impostas a vastas parcelas da população. Assim, bastante cedo filiou-se a N.O.W. (National Organization for Women), fundada e presidida por Betty Friedan. Devemos considerar também que Friedan havia à época publicado seu livro A mística feminina, de 1963, texto que certamente influenciou Millet, praticamente dez anos mais jovem do que aquela. A partir das discussões sobre qual era o problema ou a causa da insatisfação das mulheres claro que aqui essas eram ainda de uma classe privilegiada, em sua quase totalidade brancas, com certo nível de estudo e morando muito provavelmente nos subúrbios dos Estados Unidos - Friedan propunha uma necessária mudança de consciência dos sujeitos femininos como membros sociais - a tal consciousness raising, primeiro passo para mudanças estruturais que as mulheres viriam a provocar em suas comunidades, seus grupos, enfim, nas sociedades em que se inseriam.

Pode-se seguramente afirmar que o livro de Friedan, a criação da N.O.W. e tantas outras ações fomentadas a partir dos movimentos políticos pelos Direitos Civis dos anos sessenta no contexto norteamericano foram determinantes para que Kate Millet, jovem estudante de Minnesotta, se interessasse por desenvolver um estudo aprofundado sobre as relações de poder marcadas pelo sexo, dissecando a ideia de patriarcado como sustentador das desigualdades entre 
homens e mulheres, muito prejudiciais a essas últimas. Nossa proposta ao longo do presente artigo será indicar não apenas a importância histórica para o feminismo da segunda onda, aqui representada por essa produção intelectual de Millet, como também analisar possíveis diálogos com textos e propostas feministas posteriores, visando atualizar questões enfocadas, de forma, até certo ponto, pioneira, em Sexual Politics.

\section{Academia e movimentos sociais: estudos e práticas entre ondas feministas}

\begin{abstract}
Esta es escritura hablada cara a cara. This is writing spoken face to face. Escritura solitaria por falta de compañia que busca solaz en el dialogo. Writing that is solitary for lack of company and looks for solace in dialogue. Monólogo extendido hacia afuera y hablado en muchas lenguas. Monologue spoken outwardly and in tongues. (María Lugones, 1990)
\end{abstract}

Quando fui convidada pela Revista Estudos feministas, em 2009, a discutir o texto "Telling feminist stories", de Claire Hemmings, destaquei que essa autora se mostrava indignada com o fato de o feminismo da "década de setenta ter sido retratado de forma tal que teria sido apagado ou negado o forte debate desenvolvido em torno de conceitos de gênero, raça e sexualidade" (SCHNEIDER, 2009, p. 253). Hemmings estava realmente certa ao apontar, já naquele momento, que o caminho mais promissor para o feminismo estaria na direção dos feminismos "da diferença, da fragmentação, da desconstrução de noções essencialistas de identidade" (SCHNEIDER, 2009, p. 253), não sendo, portanto, justificável a simplificação exagerada tão frequentemente aplicada à história sobre os desdobramentos e avanços do feminismo ocidental.

Hemmings ironiza em seu texto as tentativas constantes de se buscar explicar os avanços das teorias feministas em etapas marcadas por um "progresso", visão evolutiva e simplificada em demasia, percebendo isso como um vício típico da lógica ocidental num sentido mais amplo, que também marca o olhar revisionista sobre o feminismo. Por essa lógica, de fato, é constantemente reforçada a ideia de

que:

\begin{abstract}
[a] mudança, que parte dos anos 70 , ingênuos e essencialistas, para a crítica do feminismo negro e da 'guerra dos sexos' dos anos 80 , e daí para os anos 90 da 'diferença' e além, mapeia a estória como progresso para além das categorias e identidades falsamente delimitadas. Uma mudança partindo do início da segunda onda, vista como politizada e unificada, passando pela entrada na academia nos anos 80 , e daí para a fragmentação em múltiplos feminismos e carreiras individuais, mapeia a estória de perda do compromisso com transformações políticas e sociais. (HEMMINGS, 2009, p. 216)
\end{abstract}

De fato, Hemmings questiona a necessidade de ter de se optar por uma das estórias vigentes sobre o feminismo, já que, por esse viés, muito provavelmente se perderia o foco dos impactos mais políticos ou revolucionários de seu campo teórico. E reafirma, ao comentar as estórias do feminismo vigentes: "[q]uando a estória é uma celebração da diferença, somos convidadas a (re)tornar ao afeto como fonte de conhecimento individual e coletivo. Quando a estória é marcada pelo pesar, o apelo é para os contextos materiais das vidas das mulheres" (HEMMINGS, 2009, p.216). Segundo a autora, seja qual for a estória que contamos sobre o feminismo a partir dessas perspectivas duais, décadas determinantes para 0 pensamento feminista acabam estereotipadas, e "o pós-estruturalismo [acaba] desempenhando o papel de ator principal no questionamento da 'mulher' como ponto de partida para a política feminista e a produção de conhecimento" (HEMMINGS, 2009, P. 216).

Esse lugar exageradamente central atrelado ao pós-estruturalismo, como se realmente só então, quase por mágica, as teóricas tivessem, do dia para a noite, passado a perceber que o significante 'mulher' não poderia dar conta de tudo que se pretendia representar através dele, acabaria por delimitar o reconhecimento de outros avanços nos debates feministas ocorridos ou mais cedo (inclusive na virada do século passado e mesmo antes), ou em outros locais (fora do mundo acadêmico ocidental), com base em teorias outras que não as dominantes a partir da segunda metade do século $\mathrm{XX}$, abafando prenúncios de debates muito interessantes mesmo para os feminismos contemporâneos. Nesse sentido, buscaremos, a partir daqui, apontar no texto de Millet 
instâncias que permitam tecer diálogos entre os argumentos desenvolvidos pela autora já em 1970 e muito do que veio a tornar-se a face talvez mais produtiva da crítica feminista na atualidade - o feminismo da diferença e das intersecções.

Ao longo da minha dissertação de mestrado, que desenvolvi no início da década de 90, como estudante da área de Letras, e que discutia e problematizava conceitos de mulher, família e loucura, Sexual Politics surgiu como base teórica no que se referia a formas de construção do gênero dentro do patriarcado. Eu citava Millet (1970, p.32, tradução minha, como todas as que seguem) e suas propostas de releituras das relações sociais: "temos de definir uma teoria da política que trate as relações de poder a partir de bases menos convencionais do que àquelas a que estamos acostumadas". Millet (1970, p.32) apostava que, através de debates sobre gênero e poder, seria possível identificar as armadilhas do sistema de gênero e seu papel determinante na construção subjetiva de homens e mulheres. Além disso, a autora argumentava que o "sexo é uma categoria com implicações políticas” (MILLET, 1970, p.32), já que, como também apontou anos mais tarde Teresa de Lauretis em sua "Tecnologia de gênero" (1987), tal arranjo facilitava que um grupo social, composto majoritariamente por homens, assumisse o controle sobre outros em praticamente todas as esferas, no caso, o grupo coletivo de mulheres, quer no espaço privado, quer no público. Millet (1970, p. 32) utiliza inclusive o conceito de Herrschaft, de Weber, para discutir tais relações de dominância e subordinação, defendendo que seria "relevante que o feminismo desenvolvesse uma psicologia e filosofia das relações de poder para além das molduras conceituais oferecidas pela política tradicional".

Obviamente essa situação que parecia quase estática, parte de arranjos sociais há muito tempo estabelecidos e constantemente reforçados, foi sofrendo modificações, na teoria e na prática, ao longo das últimas décadas, conquista de muitas mulheres que lutaram por igualdade de condições de trabalho e representação ao longo da história cultural. Contudo, se considerarmos que ainda hoje, 2020, são necessárias cotas para mulheres nos partidos políticos mundo afora, pois, de outra forma, essas provavelmente estariam ainda menos representadas na política partidária (sendo tal participação, de qualquer maneira, ainda minúscula), e o quão reduzido é o número de mulheres que assumem posição de chefia e direção nas grandes corporações, apesar de ser público e notório o maior grau de escolaridade dessas, percebemos que ainda há muito a ser feito a fim de que sujeitos femininos, num sentido amplo, diverso, a partir de vários lugares geográficos e sociais, possam atingir melhores posições dentro dos grupos em que se inserem. Nesse sentido, o que apontei em minha dissertação de mestrado, defendida em 1996, continua bastante atual; ou seja, a afirmação de Millet de que a política sexual que percorre as sociedades contemporâneas seria ideologicamente marcada pelo gênero de forma tal que haveria forte tendência, caso essa política não fosse constante e radicalmente questionada, que se repetissem ad eternum os mesmos arranjos sociais patriarcais do passado (SCHNEIDER,1996, p.16).

É possível perceber que tanto Millet como outras teóricas feministas suas contemporâneas frequentemente sustentavam seus argumentos através do questionamento do binarismo imposto até então às sociedades via lógica patriarcal. A questão de problematizar a outridade imposta às mulheres como seres sociais subalternizados em relação aos homens, sustentada pela noção de diferença sexual, foi fundamental para que essas se organizassem, dentro e fora da academia, e que suas vozes ganhassem volume e espaço. Por isso, escapar a lugares e construções ideológicas que, via de regra, atrelassem lugares de subalternidade e opressão às mulheres foi fundamental naquele momento, algo que continua tendo impactos nas práticas feministas hoje em dia.

Todas as teorizações antiessencialistas que seguiram aquela etapa foram fundamentais para fazer com que o pensamento feminista escapasse às amarras da lógica patriarcal e ao seu sistema de valor fixo e desigual. Como apontei na minha dissertação, "o feminismo rejeita todas as dadas verdades sobre 0 status dos indivíduos que estejam embasadas por 
conceitos culturais que usem a diferença sexual como desculpa para a opressão das mulheres" (SCHNEIDER, 1996, p. 17). Naquele momento, de fato, vozes integrantes das teorias feministas se rebelavam quanto à organização social essencialista imposta culturalmente e essa era uma das frentes de batalha coletiva por parte de mulheres interessadas em mudanças sociais e políticas. Portanto, descontruir - sistema de gênero e seus arranjos era algo fundamental. Releio aqui o parágrafo final dessa seção de minha dissertação, intitulado de "Gênero no patriarcado":

Em geral, a tradição ocidental é concebida e escrita a partir de um ponto de vista androcêntrico; é uma história de homens contada para outros homens, sendo esse 0 motivo pelo qual as mulheres muitas vezes dizem sentirem-se soltas no espaço em termos culturais, não tendo acesso fácil a referências femininas do passado, nem casos de sucesso mencionados na história cultural por parte de mulheres reais que existiram, vendo-se praticamente obrigadas a aceitar a história parcial da humanidade que Ihes foi oferecida, em que os homens foram as grandes referências em todas as áreas. (...) A escassez de registro sobre os feitos das mulheres, tornando suas ações invisíveis ao longo de décadas ou séculos, é terreno a ser tratado pela teoria feminista a fim de dar voz aos sujeitos femininos. (SCHNEIDER, 1996, P.16, tradução minha)

Obviamente, a partir das décadas finais do século passado muito disso passou a ocorrer, sendo questionada e modificada tal situação, sendo que diferentes mulheres passaram a ser visibilizadas, fato que Sexual Politics anunciava como parte das modificações teóricas e práticas previstas ao longo dos desdobramentos do feminismo.

Kate Millet inicialmente tece considerações em Sexual Politics sobre as formas pelas quais 0 conjunto das mulheres foi, ao longo da história, um grupo social minoritário, independentemente da questão numérica, e esclarece: "uma minoria é qualquer grupo que, devido a suas características físicas ou culturais, sofre segregação em relação a outros nas sociedades em que se inserem" (MILLET, 1970, p.93); portanto, essas formariam uma minoria por sofrerem segregação com base em interpretações culturais da diferença sexual. Ao discutir em seu primeiro capítulo praticamente um século da história anglo-americana (1830-1930) e as mulheres como parte dela, Millet (1970, p. 93) aponta que há muito a mulher casada morria "aos olhos da lei, perdendo todos os seus direitos (...). Perdia o controle sobre os seus rendimentos, não era permitido escolher seu domicílio, não podia administrar bens que the pertenciam legalmente, assinar papéis ou servir de testemunha". Percebemos aqui a construção do argumento de Millet, originalmente especialista em estudos vitorianos ao longo de seu mestrado, aos quais retorna para embasar seu questionamento quanto à falta de autonomia imposta historicamente às mulheres, mas demonstrando, em seus estudos doutorais, que, mesmo sendo constantes as tentativas de submissão e silenciamento impostos às mulheres, sempre houve resistência por parte dessas. Se foram marcadas por práticas e ideologias que idealmente as diminuíam, Millet e outras estudiosas demonstram que há inúmeros registros de mulheres que resistiram. Apresentando, por exemplo, Mary Wollstonecraft, entre outras tantas vozes femininas que não se calaram, citadas nos capítulos introdutórios de Sexual Politics, Millet reconhece existir uma estrutura ampla, diversificada, histórica, cuja finalidade sempre foi manter as mulheres afastadas das esferas do poder, fosse esse qual fosse; contudo, reconhece que também sempre houve alguma forma de escape. Mulheres que reconheciam a importância da conquista do espaço público, da independência econômica, da libertação de traços estabelecidos para além do formato de organização familiar instituída que lhes era extremamente negativa, pois essa implicava grandes sacrifícios à parcela feminina da população.

Millet ainda aponta como o trabalho (e o direito a ele), que deveria servir como ferramenta de libertação para a população, veio a tornar-se um elemento frequentemente escravizador das mulheres mais pobres, já que lhes eram oferecidas posições pouco desejáveis em minas, fábricas ou mesmo em casas de família, onde recebiam pouco e cumpriam vasta carga horária. Talvez o incêndio ocorrido em Nova lorque, em 1911, a que Millet dá destaque em seu livro, quando mais de cem trabalhadoras morreram por queimaduras ou por machucados causados pelo desesperado ato de pular pelas janelas do prédio em chamas, na tentativa de escapar do fogo em seu local 
de trabalho, tenha sido o grande marco das consequências dos péssimos enlaces históricos entre aspectos de gênero e questões trabalhistas/sociais.

Além dessa menção a trabalhadoras do século passado, que padeciam em posições extenuantes de trabalho, Millet faz também referências ao fato de que, em geral, mulheres de origem simples, na maioria das vezes não brancas, não se adequavam aos padrões da "senhora", subjetividade construída para mulheres "de bem" (leia-se de classe alta) e mais valorizadas pelo olhar social desde os séculos anteriores na maior parte das sociedades ocidentais. A autora faz inclusive menção à figura de Sojourner Truth como uma mulher negra que já apontava que o lugar de "senhora" sequer estava disponível às mulheres negras. Truth conhecia bem aquelas exclusões no contexto estadunidense, ela própria ex-escravizada, expondo a situação opressiva e de desigualdade vivenciada por mulheres negras de forma magnífica em sua fala mundialmente conhecida e verbalizada "Ain't I a woman" em uma Convenção de Mulheres em Ohio, 1851.

Millet (1970, p.111) corretamente aponta que, já na primeira onda do feminismo, ou seja, na virada do século XIX para o XX, no contexto estadunidense

(...) foi a luta contra a escravatura que deu força inicial ao movimento para a emancipação das mulheres. Foi a propósito deste problema que as mulheres tiveram a sua primeira experiência política e puderam aperfeiçoar os métodos a utilizar em seguida na maior parte das suas campanhas e até ao final do século: contestação e agitação destinadas a manter o público informado.

Ainda que se possa criticar que uma teórica branca, deslocada da experiência vivida de escravização pelos povos negros, mencione essa situação como um problema chave e uma mola mestra para o feminismo (branco) da primeira onda, há que se considerar que tal desvelamento das injustiças raciais, para além das de gênero, seriam fundamentais algumas décadas mais tarde, ao atingir outros territórios, como os da esfera acadêmica. Além disso, a causa antiescravagista prometia naquela virada de século uma unidade nunca antes vista entre mulheres no território público e político estadunidense, ação que se justificava mais facilmente aos olhos da sociedade em geral por ser uma luta ética, por garantia da vida humana. Nesse sentido, a construção da união entre mulheres pela abolição da escravatura, que defendia a libertação dos povos negros, tanto para homens como mulheres, foi, de fato, um momento de rebeldia e visibilidade dos sujeitos femininos em sociedades ainda largamente racistas e discriminatórias. Há prenúncios óbvios em Sexual Politics, bem como em publicações de outras feministas tanto da primeira como da segunda onda, que o feminismo teria, sim, de falar por e a partir da perspectiva de diferentes mulheres; ou melhor, teria de se subdividir em diferentes feminismos a fim de dar conta de tanta diversidade e escutar diretamente diferentes vozes de mulheres com problemas diversos a serem priorizados, que já vinham se manifestando, porém sem serem escutadas, há um longo tempo.

Mesmo considerando, como lemos nas linhas acima, a importância das lutas antiescravagistas como fundamentais para a organização política das mulheres e feministas em geral, Millet apontava precocemente que havia um estratagema, parte de um macro plano patriarcal, no sentido de colocar sujeitos femininos em posições opostas, o que eficazmente dividiu mulheres por classes sociais e grupos raciais, impedindo uma profunda solidariedade naqueles momentos iniciais do movimento feminista. Nesse contexto, à mulher menos favorecida (muitas vezes pobre e não branca) só restaria sonhar "tornar-se uma senhora, (...) através da proteção sexual de um homem", nas palavras (creio eu, irônicas) de Millet (1970, p.102). Mesmo reconhecendo que às brancas essa posição social de subjetividade era verossímil, Millet (1970, p.102) esclarece que "desmascarar o espírito cavalheiresco e denunciar sua cortesia como manobra sutil" era algo fundamental para os avanços das mulheres em geral, como seres sociais que eram. Ela ainda afirmaria ser fundamental "reconciliar as classes, unir numa causa comum a grande senhora e a operária, a prostituta e a respeitável mãe de família" (MILLET,1970, p.103), vendo em tal união o possível sucesso da revolução. Há um prenúncio aí da ideia de irmandade, de sisterhood, de um apoio mútuo possível de ser estabelecido entre mulheres diferentemente posicionadas. 
Bem da verdade, o que se seguiu não foi uma única revolução das mulheres, apesar de essa ter sido iniciada crendo em unidade possível. Após ler e reler teóricas como Kate Millet, Teresa de Lauretis e outras das décadas de setenta e oitenta, conclui em minha dissertação de mestrado que,

\begin{abstract}
A teoria feminista tem consciência das diferenças entre as mulheres e, portanto, não pretende impor uma categoria homogênea de "mulher"; ao contrário, as feministas levam, sim, em conta diferenças raciais e sociais entre mulheres, mas também reconhecem experiências e pontos de vista similares entre essas, construídos a partir de lugares bastante diferentes. (SCHNEIDER, 1996, p.22)
\end{abstract}

Contudo, a partir das décadas seguintes podemos observar que talvez mais do que "experiências similares" entre mulheres, o que teve destaque foram, de fato, as especificidades e diferenças vivenciadas por mulheres que não se percebiam como brancas ou não eram heterossexuais, ou não tinham acesso a condições básicas de saúde e educação; ou seja, aquelas que por muito tempo não foram sujeitos do discurso feminista dominante, mas que viriam a assumir as frentes feministas mais promissoras, no campo teórico e prático nos desdobramentos das primeiras ondas do movimento. Não era apenas o patriarcado que impedia a unidade entre mulheres diferentemente posicionadas, mas vários outros fatores, entre os quais a percepção de que apostar em alianças e parcerias entre mulheres diferentes seria mais promissor do que buscar características comuns entre elas. Obviamente a solidariedade e a cooperação (ainda que muitas vezes problemática e tensa) assumiu papel determinante na construção de agendas feministas a partir da percepção da diferença interna, ou seja, entre mulheres.

Assim, podemos afirmar que a mencionada revolução das mulheres, tão destacada por Millet, se subdividiu, ainda que mantendo elos em comum entre os diferentes grupos. Sempre houve trocas, mas também atritos óbvios. Como bem aponta Gloria Anzaldúa (1990, p. xv) em sua introdução à antologia Making face, making soul, às mulheres não-brancas sempre se impôs o uso de máscaras, já que tinham necessariamente de se adaptar a várias situações desfavoráveis através de diferentes formas de se colocar, com diferentes caras. Como aponta essa autora, "as máscaras que somos forçadas a usar causam uma lacuna entre nossa personalidade intersubjetiva e a persona que apresentamos ao mundo" (tradução minha). Essa antologia específica, que dá sequência a outra intitulada This bridge called my back (ANZALDÚA e MORAGA), dos anos oitenta, buscou delimitar as diferenças entre mulheres $\mathrm{e}$ feministas, propondo uma "descostura" das máscaras, que exporia as várias camadas cerzidas, as várias caras sobrepostas e, por baixo dessas, as sobreposições de diversas opressões. Nesse momento do dissecar as máscaras, não apenas as que expunham a opressão sexual apareceram nitidamente, mas, principalmente, a persistente discriminação étnico-racial que percorria toda a existência de sujeitos não brancos nas sociedades pós-coloniais em que a escravização e/ou opressão de nativos e negros ocorrera.

Anzaldúa afirma que depois da publicação da antologia This bridge called my back esperou que imediatamente algum outro livro viria, dando voz a mais e mais mulheres de cor. Assim, quando foi contratada para lecionar na Universidade de Santa Cruz, não tendo ainda se deparado com outras produções do tipo da antologia citada, resolveu que, já que nenhuma coletânea mais ampla surgira a fim de simplificar o acesso a bibliografias mais descentradas para seus cursos, começaria a coletar tal material por conta própria. Por fim, acabou estruturando, a partir desses levantamentos, uma segunda antologia de mulheres estadunidenses de cor, que assumiu papel importante nos estudos literários, feministas e culturais, causando um impacto muito mais amplo do que apenas para o público dos cursos universitários que, como professora, Anzaldúa então oferecia. Ela esclarece que a antologia Making soul, making face surgiu com o intuito de "confrontar o racismo no movimento de mulheres brancas de uma maneira mais completa, pessoal, direta, empírica e teórica" (p.xvi), mencionando as possibilidades e dificuldades da construção de alianças entre mulheres. 


\section{Breves conclusões}

Susana B. Funck (in SCHNEIDER, 2008, p.7) em seu prefácio ao livro que publiquei sobre pesquisas na literatura indígena estadunidense, apontava que, a partir da segunda metade do século XX, "questões de raça/etnia, classe, gênero e nacionalidade suscitaram olhares oblíquos, lançados das margens para o centro, que embaçavam os enfoques formais mais monolíticos, causando incertezas e desvendando diferenças". Logo na introdução ao mesmo livro, eu mesma reconhecia uma mudança nas relações de poder na arena cultural estadunidense, apontando que

(...) a literatura americana de origem indígena, latina, asiática, africana, bem como a produzida sob a ótica queer, lésbica ou gay entraram com força total no mercado editorial, salientando novos tópicos e pontos de vista que passaram a exigir maior atenção e reconhecimento. (SCHNEIDER, 2008, p. 15)

De fato, o feminismo, em sua vertente literária, cultural e política, sempre pretendeu trazer as mulheres e seus textos para a esfera pública, a fim de que fizessem mais claramente parte da visão que se tem das culturas em geral, assumindo ali posições de poder e decisão. Assim, definições de subjetividade binariamente limitadas foram questionadas pela desessencialização das identidades, desestruturando o binarismo atrelado a gênero, raça, classe, entre outros. Já as visões pós-coloniais e decoloniais questionaram as histórias do imperialismo, que sobreviviam através de repetições de paradigmas não problematizados. Como Ann Phoenix (1988) muito bem apontou, as identidades devem ser lidas como constantemente em processo de formação, e não como algo fixo, totalmente finalizado e determinado. É exatamente essa compreensão de processo que nos faz perceber a relevância de estudos feministas anteriores como importantes e com impacto inclusive nos questionamentos quanto à distribuição de poder, não apenas entre homens e mulheres, mas entre grupos diversos de organização de indivíduos por afinidades ou identificações outras que o gênero.

A partir da concepção de Trinh Minh-há (1989) de que as teorias revolucionárias seriam aquelas que questionam o "conhecimento fossilizado", podemos inferir que qualquer fossilização concretizada como resultado de conquista aparentemente estável de um terreno tende a fazer com que determinadas lógicas e conceitos se tornem mais estabelecidos e aceitos com o passar do tempo. Ou seja, toda teoria deveria ser questionada em seu eventual potencial fossilizador. Assim, acreditamos que se algo possa ter sido parcialmente fossilizado nos discursos feministas anteriores, estratégia em um momento de fundamentação das estruturas do feminismo como prática social, certamente 0 fato de as teorias feministas contemporâneas estarem ainda mais atentas às tendências de fossilização dentro de seu próprio discurso colabora com a constante renovação, alternância de poder entre visões que compõem agendas feministas do passado até os dias atuais. Se a problematização do gênero veio por meio das mulheres, acadêmicas ou não, mas que vivenciaram seus aspectos nefastos em suas vidas e carreiras, outras problematizações de questões estruturais, como raça e racismo, sexualidade, classe social, foram colocadas no centro do debate feminista frequentemente por aquelas que sentiram o problema na pele, no corpo.

Quando Anzaldúa (1990, p. xix, tradução minha) afirma que "como sobreviventes do Racismo, as mulheres de cor sofrem de estresse crônico e de uma contínua síndrome pós-traumática por estresse, vivida por sobreviventes de guerras", fica claro que, para uma intelectual negra, torna-se impossível tratar de gênero sem tratar de raça. Assim como o gênero deve ser preocupação de homens e mulheres interessados e comprometidos com a construção de sociedades mais justas, o debate sobre o racismo e a luta antirracista também tem de ser desenvolvido por todos e todas interessados/as em construções sociais mais igualitárias no que diz respeito à raça; no caso das mulheres de cor isso não é opção, o racismo as confronta a todo o momento, por ser estrutural e estar instalado em todas as instituições nas mais variadas comunidades. Portanto, um diálogo que permita e incentive pontes entre os discursos feministas anteriores, que ajudaram a dar voz de forma inaugural às mulheres em grupos sociais que não pretendiam 
priorizá-las, e os discursos que dão posição de destaque às subjetividades negras, com todos os atritos e tensões que certamente fazem parte dessa conversa, pode propiciar encontros, conexões e intersecções férteis entre os diversos feminismos vigentes. Kate Millet certamente participou, em alguma instância, da construção de uma maior visibilidade em relação às mulheres no mundo contemporâneo e as repercussões disso são inegáveis no momento contemporâneo.

Acredito que o fato de ter conservado Sexual Politics entre textos que continuam iluminando minha estante de livros, quase trinta anos após a utilização inicial que fiz dele e meio século após sua publicação indica, a meu ver, seu potencial de cruzar décadas, trazer diferentes agendas para o debate, colocando em contato vozes feministas de tempos e contextos diversos a partir de pontos fundamentais, através dos quais alguma coalizão sempre pode ser construída, questionada e reconstruída.

Voltando a tal publicação nesse momento, percebo mais uma vez a amplitude e profundidade do estudo desenvolvido por Millet, que perpassa conhecimentos de áreas da Sociologia, Psicologia, da Economia, da História, da Filosofia e das Letras, mantendo sua importância e vigor praticamente intactos. Continuo avaliando Sexual Politics como um dos livros mais fundamentais a que tive acesso ao longo dos anos estudantis ou, depois, como professora interessada nas teorias feministas e de gênero. No posfácio ao seu livro, é interessante observar que Millet aponta já perceber mudanças no que se referia à cultura de guerras e virilidade, que estaria "em baixa", questionamentos certamente atrelados a um novo feminismo que se reconhecia como vinculado à luta por direitos civis. Millet aponta que (1970, p. 501):

A mudança em valores fundamentais que a coalizão entre grupos de expropriados negros, jovens, mulheres, pobres - almeja são pertinentes não apenas para concretização da revolução sexual, mas para um ímpeto em direção à liberdade no que se refere a papéis classificatórios e prescritivos, sexuais ou outros.

Cinquenta anos após a formulação destas propostas teóricas, essas ainda são muito úteis como ferramenta, embasando a busca por mudanças sociais e culturais, o que justifica por si só esse dossiê comemorativo dedicado ao livro de Millet, do qual me alegro em fazer parte.

\section{Referências}

ANZALDUA, Gloria (ed.). Making face, making soul: creative and critical perspectives by feminists of color. San Francisco: aunt lute books, 1990.

HEMMINGS, Clare. Contando estórias feministas. Trad. Ramayana Lira. Estudos Feministas, Florianópolis, 17(1): 296, janeiro-abril, 2009, p. 215 $-241$.

FRIEDAN, BETTY. A mística feminina. Trad. Áurea B Weissenberg. Petrópolis/RJ: Ed. Vozes Ltda, 1971.

FUNCK, Susana B. Prefácio in SCHNEIDER, Liane. Escritoras indígenas e a literatura contemporânea dos EUA. João Pessoa: Ed. UFPB, 2008

LAURETIS, Teresa de. Tecnologies of gender. Indianapolis, Indiana University Press, 1987.

MILLET, Kate. Sexual politics. New York: Ballantine books, 1970 .

MINH-HÁ, Trinh T. Woman, native, other: writing postcoloniality and feminism. Bloomington: Indiana University Press, 1989.

MORAGA, Cherrie \& ANZALDUA, Gloria (eds.). This bridge called my back: writings by radical women of color. Latham, New York: Kitchen Table Press, 1983.

PHOENIX, Ann. (Re)constructing gendered and ethnicised identities: are we all marginal now? Utrecht, 1998. Aula inaugural na Faculdade de Humanidades de Utrecht.

SCHNEIDER, Liane. Marge Piercy's and Doris Lessing's female subjects: the politics of representation. Dissertação de mestrado. Porto Alegre: UFRGS, 1996.

Escritoras indígenas e a literatura contemporânea dos EUA. João Pessoa: Ed. UFPB, 2008.

\footnotetext{
"Contando estórias feministas" e a reconstrução do feminismo recente. Estudos Feministas, Florianópolis, 17(1): 296, janeiro-abril, 2009 , p. $251-263$

TRUTH, Sojourner. "Ain't I a woman?" In: GILBERT, Sandra \& GUBAR, Susan (eds.) The Norton anthology of literature by women. 2nd ed. New York: W.W. Norton \& Company, 1996, p. 370.
} 
SCHNEIDER, Liane. Kate Millet, Sexual Politics e os diálogos entre diferentes paradigmas e ondas feministas. Signo, Santa Cruz do Sul, v. 45, n. 84, p. 2-11, nov. 2020. ISSN 1982-2014. Disponível em: $<$ https://online.unisc.br/seer/index.php/signo/article/view/15579> doi:https://doi.org/10.17058/signo.v45i84.15579. 